\title{
A CONVIVÊNCIA ÉTICA X VIOLÊNCIA NA ESCOLA: UM DESAFIO CONTEMPORÂNEO
}

\section{APRESENTAÇÃO}

Nesta seção, a temática "convivência ética X violência” é abordada a partir de determinadas contingências que, apesar de não restritas ao universo escolar, encontram nele um importante e valioso lócus de manifestação. Importante porque na escola as emoções advindas das relações interpessoais reluzem aos educandos com intensidade sui generis, incidindo na construção de sua moralidade. Valioso, pois, esta condição oportuniza à escola, na medida em que eleva a convivência ao status de objeto sistemático de reflexão, o desenvolvimento de práticas intencionais e de conhecida eficácia voltadas à formação dos valores morais que tanto desejamos.

Para isso, não é possível prescindir, conforme nos têm demonstrado a literatura mundial, de uma formação de professores capaz de subsidiá-los para poderem trabalhar com a questão da convivência como um valor, libertando-os, assim, das amarras que lhes atam as mãos diante da tarefa de superar os problemas de convivência que se perpetuam na insuficiência de valores morais. Torna-se fato a tarefa de compreender a dinâmica do desenvolvimento moral e dos processos de resolução de conflitos de crianças e adolescentes para que se possa intervir.

Da mesma forma, urge a reflexão sobre formas inusitadas de violência que se sobrepõem aos muros da escola, como o cyberbullying e outras formas de cyber agressão e, novamente, as formas pelas quais a sociedade moderna pode enfrentar o desafio da formação humana - justa, generosa, respeitosa - no mundo real e virtual. Estes são os pontos cruciais destacados nessa seção.

Assim esta seção apresenta três contribuições importantes à reflexão da temática proposta: 
Artigo 01: Bullying e cyberbullying: quando os valores morais nos faltam e a convivência se estremece.

Artigo 02: Quando a violência virtual nos atinge: os programas de educação para a superação do cyberbullying e outras agressões virtuais.

Artigo 03: Os conflitos entre alunos de 8 e 9 anos - a provocação e a reação ao comportamento perturbador: o que os educadores devem saber.

Luciene Regina Paulino TOGNETTA ${ }^{1}$ Darlene Ferraz KNOENER ${ }^{2}$ Sanderli Ap. Bicudo BOMFIM ${ }^{3}$ Sandra Trambaiolli DE NADAI ${ }^{4}$ Thais Cristina Leite BOZZA ${ }^{5}$ Telma Pileggi VINHA ${ }^{6}$ Lívia Maria Ferreira da SILVA ${ }^{7}$

${ }^{1}$ Universidade Estadual Paulista (Unesp), Araraquara - SP - Brasil. Professora do Departamento de Psicologia da Educação Pedagoga. Líder do GEPEM - UNESP/UNICAMP. E-mail: lrpaulino@uol.com.br

${ }^{2}$ Universidade Estadual Paulista (Unesp), Araraquara - SP - Brasil. Mestranda em Educação Escolar. Membro do GEPEM - UNESP/UNICAMP. E-mail: darlene.knoener@gmail.com

${ }^{3}$ Universidade Estadual Paulista (Unesp), Araraquara - SP - Brasil. Mestranda em Educação Escolar. Membro do GEPEM - UNESP/UNICAMP. E-mail: sanderli.bicudo@gmail.com

${ }^{4}$ Universidade Estadual Paulista (Unesp), Araraquara - SP - Brasil. Mestranda em Educação Escolar. Membro do GEPEM - UNESP/UNICAMP.. E-mail: sctnadai@ hotmail.com

${ }^{5}$ Universidade Estadual de Campinas (Unicamp), Campinas - SP - Brasil. Doutoranda em Educação na área de Psicologia. Membro do GEPEM - UNESP/UNICAMP. E-mail: thaisbozza@ hotmail.com

${ }^{6}$ Universidade Estadual de Campinas (Unicamp), Campinas - SP - Brasil. Professora do departamento de psicologia educacional da UNICAMP. Membro do Laboratório de Psicologia Genética da UNICAMP e líder do GEPEM - UNESP/UNICAMP. E-mail: telmavinha@uol.com.br

${ }^{7}$ Doutora em Educação pela Unicamp, com estágio sanduíche na Harvard Graduate School of Education. Membro do Laboratório de Psicologia Genética da UNICAMP e do GEPEM - UNESP/UNICAMP. Email: liviamfsilva@gmail.com 